\title{
Sex differences in clinical characteristics and long-term outcomes in patients with vasospastic angina: results from the VA- Korea registry, a prospective multi-center cohort
}

Hack-Lyoung Kim', Sang-Ho Jo ${ }^{2^{*}}$ (D), Hyun-Jin Kim³ ${ }^{3}$ Min-Ho Lee ${ }^{4}$, Won-Woo Seo ${ }^{5}$ and Sang Hong Baek ${ }^{6}$

\begin{abstract}
Background: Sex differences in clinical characteristics and prognosis of vasospastic angina (VA) have not been well elucidated. This study was performed to investigate sex-specific characteristics and predictors for long-term clinical outcomes in patients with VA.

Methods: We analyzed 1838 patients (55 years and 62\% male) who were diagnosed with definite $(n=680)$ or intermediate $(n=1212)$ VA in ergonovine provocation test from a nation-wide VA registry. The primary study endpoint was composite events including cardiac death, acute coronary syndrome, ventricular tachycardia or fibrillation, and atrioventricular block during clinical follow-up.

Results: Male patients were younger, and there were more smokers and alcohol drinkers in male patients than in female patients. During the median follow-up period of 760 days (interquartile range, 336-1105 days), there were 73 cases (3.97\%) of composite events. There was no sex difference in the occurrence of composite events (log-rank $p=0.649$ ). Concomitant significant ( $\geq 50 \%$ ) organic coronary stenosis was associated with worse clinical outcomes in both male (hazard ration [HR], 1.97; 95\% confidence interval [CI], 1.01-3.85; $p=0.047)$ and female (HR, 3.26; 95\% $\mathrm{Cl}, 1.07-9.89 ; p=0.037$ ) patients. Obesity (body mass index $\geq 25 \mathrm{~kg} / \mathrm{m}^{2}$ ) was associated with better prognosis in female VA patients ( $\mathrm{HR}, 0.22 ; 95 \% \mathrm{Cl}, 0.07-0.68 ; p=0.008)$. Even when only patients with definite diagnosis of VA were considered, there was no significant sex difference in clinical outcomes (log-rank $p=0.876$ ).

Conclusions: In VA patients, there were several different clinical characteristics according to sex; however, longterm clinical outcome was similar between sexes. Significant organic coronary stenosis in both sexes and low body mass index $\left(<25 \mathrm{~kg} / \mathrm{m}^{2}\right)$ in females were associated with worse prognosis in VA patients.
\end{abstract}

Keywords: Clinical characteristics, Prognosis, Sex difference, Vasospastic angina

\footnotetext{
*Correspondence: sophi5neo@gmail.com

${ }^{2}$ Division of Cardiology, Department of Internal Medicine, Hallym University Sacred Heart Hospital, Anyang, Korea

Full list of author information is available at the end of the article
}

(c) The Author(s). 2020 Open Access This article is licensed under a Creative Commons Attribution 4.0 International License, which permits use, sharing, adaptation, distribution and reproduction in any medium or format, as long as you give appropriate credit to the original author(s) and the source, provide a link to the Creative Commons licence, and indicate if changes were made. The images or other third party material in this article are included in the article's Creative Commons licence, unless indicated otherwise in a credit line to the material. If material is not included in the article's Creative Commons licence and your intended use is not permitted by statutory regulation or exceeds the permitted use, you will need to obtain permission directly from the copyright holder. To view a copy of this licence, visit http://creativecommons.org/licenses/by/4.0/. The Creative Commons Public Domain Dedication waiver (http://creativecommons.org/publicdomain/zero/1.0/) applies to the data made available in this article, unless otherwise stated in a credit line to the data. 


\section{Introduction}

Vasospastic angina (VA) is characterized by recurrent chest pain, not related to exertion, with dynamic ST segment changes in electrocardiograms, which is caused by coronary artery spasm [1-3]. In general, VA is known to have a better long-term prognosis compared to atherosclerotic coronary stenosis due to its good response to vasodilators [4-6]. In some cases, however, VA can cause fatal complications such as acute myocardial infarction and ventricular arrhythmia leading to sudden cardiac death; thus, vasodilator therapy should not be neglected $[7,8]$.

Over the past decade, effort to understand sex differences has continued, and realized the importance of cardiovascular disease in females $[9,10]$. In particular, sex differences in coronary vasomotor function are relatively well known. It has been suggested that increased coronary reactivity and microvascular dysfunction play significant roles in ischemic heart disease in females [10-12]. VA is also caused by the functional abnormalities of the coronary artery; however, sex differences in VA have not yet been well studied. In particular, VA is highly prevalent in males $[1,2]$, and there has been limited data on the characteristics of female patients with VA. Until now, only a few studies have addressed sex difference in VA [13-17]. Among these studies, only two studies have investigated sex differences in long-term VA prognosis; however, sex-specific factors determining long-term clinical outcome of VA are inconsistent [13, 15]. Therefore, using a large number of VA patients from the prospective nation-wide registry database, this study was performed to elucidate more clearly sex differences in clinical characteristics, long-term clinical outcomes of $\mathrm{VA}$, and to find out sex-related risk factors associated with VA prognosis.

\section{Methods}

\section{Study patients}

Data was from the nation-wide prospective registry of VA in Korea (VA-Korea) [18, 19]. Eleven tertiary hospitals in South Korea participated in this registry. Between May 2010 and June 2015, consecutive patients (>18 years) with suspected VA and underwent invasive coronary angiography (CAG) and ergonovine (EG) provocation test were enrolled. Patients who had a normal or mild ( $<50 \%$ luminal diameter narrowing) coronary atherosclerotic stenosis at baseline CAG were eligible. However, EG provocation test was also performed in some patients with intermediate (50-70\%) organic stenosis by the attending physician's discretion when VA was strongly suspected. Patients having malignancy, endstage renal disease on dialysis, and inflammatory disease were excluded [20]. Initially 2960 patients with suspected VA were enrolled, and 868 patients with negative results in EG provocation test were excluded. After further exclusion of 254 patients with missing data and loss of clinical follow-up, the remaining 1838 patients were analyzed in this study. The study protocol complied with the Declaration of Helsinki, and was approved by the Institutional Review Board of each participating hospital. Written informed consent was obtained from each patient.

\section{Data collections}

Data was collected from the VA-Korea registry database through a web-based electronic data-capture system containing an electronic case report form. Body mass index (BMI) was calculated by dividing body weight in kilograms by the square of height in meters $\left(\mathrm{kg} / \mathrm{m}^{2}\right)$. Information on cardiovascular risk factors was obtained, which included hypertension, diabetes mellitus, dyslipidemia, cigarette smoking, and alcohol drinking. The blood levels of important biochemical variables, including hemoglobin, creatinine, glucose, total cholesterol, lowdensity lipoprotein cholesterol, high-density lipoprotein cholesterol, and triglyceride at admission, were identified. Left ventricular ejection fraction was obtained using Simpson's biplane method during transthoracic echocardiography. Cardiovascular medications, including antiplatelets, calcium channel blockers, renin-angiotensin system blockers, beta-blockers, vasodilators, and statin were also assessed.

\section{Invasive CAG and EG provocation test}

CAG was performed by well-trained cardiologists according to the standardized method [21]. Vasoactive medications were stopped at least $48 \mathrm{~h}$ before CAG. CAG was performed via the right femoral artery without the use of nitroglycerin. In cases of no significant atherosclerotic coronary stenosis on CAG, EG provocation test was performed using the same protocol in all participating hospitals [18, 20, 22]. In some patients, even with significant narrowing of the coronary arteries, EG provocation was performed when the lesions did not match the clinical feature or they were suspected of accompanying VA. Provocation test was started with the right coronary artery (RCA) and then the left coronary artery (LCA). EG was diluted in saline and injected slowly into the coronary arteries over 2-3 min. If coronary spasm was not induced, EG doses were gradually increased from 10 to $20 \mu \mathrm{g}$ and $40 \mu \mathrm{g}$ during the RCA angiography, and from 20 to $40 \mu \mathrm{g}$ and $60 \mu \mathrm{g}$ during the LCA angiography. Once coronary spasm was provoked, 200 $\mu \mathrm{g}$ of nitroglycerin was immediately injected into coronary artery. Chest pain and electrocardiographic (ECG) changes were also recorded during the procedure. Definite VA was defined as a total $(100 \%)$ or subtotal (>90\% luminal diameter narrowing) occlusion of the index 
coronary artery accompanied by ischemic symptoms and/or ECG changes. An ischemic ECG change was defined as an ST segment elevation or depression $>0.1 \mathrm{mV}$ or a negative $\mathrm{U}$-wave in at least two contiguous leads [22]. An intermediate result was defined as $50-90 \%$ luminal narrowing with or without ischemic symptoms and/or ECG changes. A negative result was defined as both RCA and LCA EG provocation tests with $<50 \%$ luminal narrowing without ischemic symptoms nor ECG changes. Cather-induced spasm was excluded. The CAG results were analyzed in detail by dividing each coronary artery and its segments. Angiographic findings were analyzed on-line or off-line using a dedicated quantitative coronary angiography program or manual assessment by investigators in each hospital who were not involved in the study. In addition, investigators at the core laboratory of Seoul St. Mary's Hospital in South Korea confirmed the angiographic data off-line by visual assessment in a blinded fashion [18]. Significant organic stenosis of the coronary artery was defined as luminal diameter narrowing $\geq 50 \%$ that did not respond to intracoronary nitrate infusion. Angiographic finding of typical case of VA is demonstrated in Fig. 1.

\section{Clinical events}

Cardiovascular events were assessed during the followup. The primary endpoint was a composite of cardiac death, acute coronary syndrome, ventricular tachycardia or fibrillation, and atrioventricular block. Cardiac death was defined as sudden unexplained death, and death caused by acute coronary syndrome, pump failure, and cardiac arrhythmia [18, 19]. Acute coronary syndrome included acute myocardial infarction and unstable angina, which were diagnosed based on typical ischemic symptoms and ECG changes with (acute myocardial infarction) or without (unstable angina) cardiac enzyme elevation [23]. Ventricular tachycardia or fibrillation and atrioventricular block were confirmed in ECG.

\section{Statistical analysis}

Continuous variables are expressed as mean \pm standard deviation, and categorical variables as percentages. Continuous variables were compared using Student's $t$ test, and categorical variables using the Chi-square test between sexes. Event-free survival rates between the two groups were demonstrated using Kaplan-Meier survival curves and compared using the log-rank test. Independent risk factors for composite events were analyzed using Cox proportional hazard regression analysis. The following variables were considered to be potential confounders, and were controlled during the multivariable analyses: age, BMI, hypertension, diabetes mellitus, cigarette smoking, significant atherosclerosis, spasm severity, and the use of calcium channel blockers. A $p$ value of $<0.05$ was considered statistically significant. All statistical analyses were conducted using the Statistical Package for the Social Science (SPSS) 20.0 (IBM Co., Armonk, NY, USA).

\section{Results}

\section{Baseline clinical characteristics}

The mean age of total study patients $(n=1838)$ were $55.1 \pm 11.3$ years, and $1141(62.1 \%)$ were male. The baseline clinical, ECG, and angiographic characteristics of the study patients according to sex are shown in Table 1. Male patients were younger and had higher systolic and diastolic blood pressures compared to female patients. Cigarette smoking and alcohol drinking were

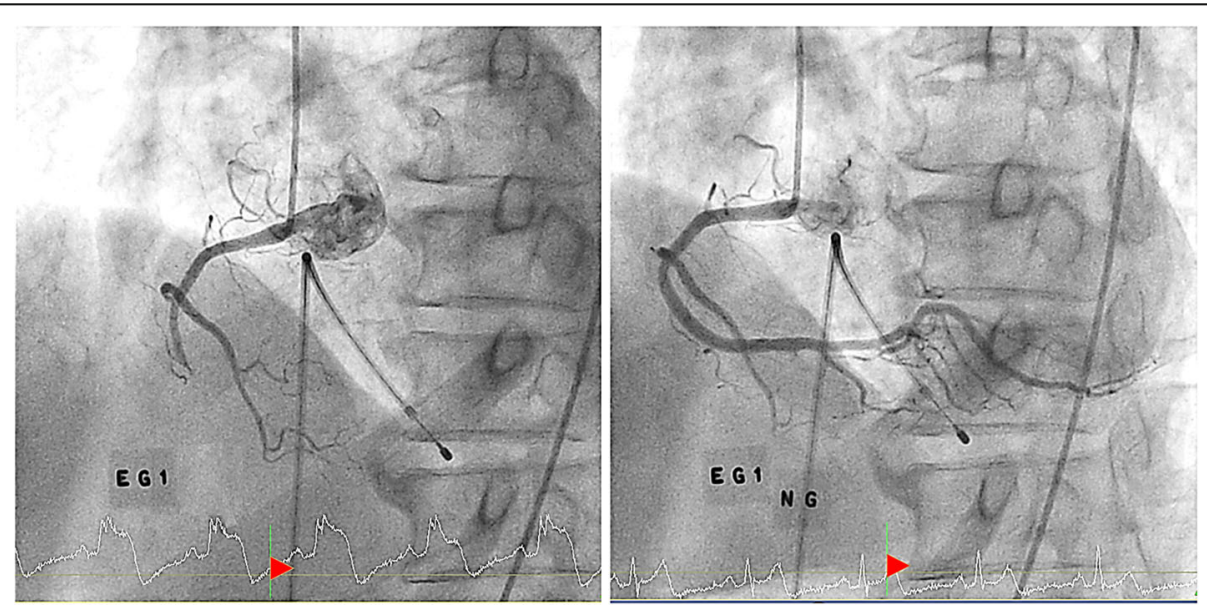

Fig. 1 Coronary angiographic findings of a typical case of vasospastic angina. (Left figure) Angiography of right coronary artery shows totally occluded coronary artery after the first dose of intracoronary ergonovine (EG1). At the bottom of the image, ST segment elevation was notable at the time of coronary artery spasm. (Right figure) After injection of nitroglycerin into coronary artery (NG), coronary spasm was relieved and normal coronary artery was visualized. ST segment elevation was also normalized after nitroglycerin injection 
Table 1 Characteristics of study patients

\begin{tabular}{|c|c|c|c|}
\hline Characteristic & Male $(n=1141)$ & Female $(n=697)$ & $p$ value \\
\hline Age, years & $54.0 \pm 11.5$ & $56.9 \pm 10.6$ & $<0.001$ \\
\hline Body mass index, $\mathrm{kg} / \mathrm{m}^{2}$ & $24.7 \pm 3.02$ & $24.7 \pm 3.8$ & 0.839 \\
\hline Systolic blood pressure, mmHg & $127 \pm 18$ & $123 \pm 19$ & $<0.001$ \\
\hline Diastolic blood pressure, mmHg & $78.2 \pm 12.4$ & $75.0 \pm 11.7$ & $<0.001$ \\
\hline \multicolumn{4}{|l|}{ Cardiovascular risk factor } \\
\hline Hypertension & $437(38.3)$ & $260(37.3)$ & 0.659 \\
\hline Diabetes mellitus & $121(10.6)$ & $56(8.0)$ & 0.067 \\
\hline Dyslipidemia & $176(15.5)$ & $124(17.8)$ & 0.188 \\
\hline Previous CAD & $147(12.9)$ & $74(10.6)$ & 0.142 \\
\hline Current smoking & $465(41.5)$ & $37(5.4)$ & $<0.001$ \\
\hline Alcohol drinking & $655(57.4)$ & $107(15.4)$ & $<0.001$ \\
\hline \multicolumn{4}{|l|}{ Clinical diagnosis } \\
\hline Angina & $1,036(90.9)$ & 639 (91.9) & 0.433 \\
\hline Acute myocardial infarction & $25(2.2)$ & $9(1.3)$ & 0.166 \\
\hline Cardiac arrest & $21(1.8)$ & $6(0.9)$ & 0.091 \\
\hline Syncope & $18(1.6)$ & $4(0.6)$ & 0.055 \\
\hline Ventricular tachycardia or fibrillation & $9(0.8)$ & $3(0.4)$ & 0.552 \\
\hline Atrioventricular block & $1(0.1)$ & 0 & 0.999 \\
\hline \multicolumn{4}{|l|}{ Laboratory finding } \\
\hline Hemoglobin, g/dL & $14.5 \pm 1.5$ & $12.8 \pm 1.2$ & $<0.001$ \\
\hline Creatinine, mg/dL & $0.88 \pm 0.38$ & $0.64 \pm 0.16$ & $<0.001$ \\
\hline Glucose, mg/dL & $114 \pm 39$ & $106 \pm 35$ & $<0.001$ \\
\hline Total cholesterol, mg/dL & $171 \pm 36$ & $178 \pm 36$ & $<0.001$ \\
\hline LDL cholesterol, mg/dL & $101 \pm 31$ & $106 \pm 31$ & 0.004 \\
\hline HDL cholesterol, mg/dL & $44.3 \pm 12.1$ & $50.3 \pm 13.0$ & $<0.001$ \\
\hline Triglyceride, mg/dL & $156 \pm 111$ & $122 \pm 89$ & $<0.001$ \\
\hline Left ventricular EF, \% & $64.2 \pm 6.8$ & $64.8 \pm 6.3$ & 0.073 \\
\hline \multicolumn{4}{|l|}{ ECG finding } \\
\hline Normal sinus rhythm & $1,013(88.9)$ & $646(92.7)$ & 0.007 \\
\hline Atrial fibrillation or atrial flutter & $19(1.7)$ & $10(1.4)$ & 0.699 \\
\hline Ventricular tachycardia & $2(0.2)$ & 0 & 0.529 \\
\hline Ventricular fibrillation & $8(0.7)$ & $3(0.4)$ & 0.549 \\
\hline Atrioventricular block & $13(1.1)$ & $7(1.0)$ & 0.999 \\
\hline ST segment elevation & $93(8.2)$ & $9(1.3)$ & $<0.001$ \\
\hline ST segment depression & $12(1.1)$ & $5(0.7)$ & 0.468 \\
\hline T inversion & $21(1.8)$ & $25(3.6)$ & 0.020 \\
\hline \multicolumn{4}{|l|}{ CAG finding } \\
\hline \multicolumn{4}{|l|}{ Atherosclerosis of total coronary artery } \\
\hline Any & $448(39.3)$ & $191(27.5)$ & $<0.001$ \\
\hline Significant (> 50\%) & 159 (13.9) & $60(8.6)$ & 0.001 \\
\hline \multicolumn{4}{|l|}{ LM atherosclerosis } \\
\hline Any & $14(1.2)$ & $5(0.7)$ & 0.296 \\
\hline Significant (> 50\%) & 0 & 0 & 1.000 \\
\hline Mean stenosis & $28.5 \pm 6.3$ & $24.0 \pm 5.4$ & 1.670 \\
\hline
\end{tabular}


Table 1 Characteristics of study patients (Continued)

\begin{tabular}{|c|c|c|c|}
\hline Characteristic & Male $(n=1141)$ & Female $(n=697)$ & $p$ value \\
\hline \multicolumn{4}{|l|}{ LAD atherosclerosis } \\
\hline Any & $304(26.7)$ & $140(20.1)$ & 0.002 \\
\hline Significant (> 50\%) & $100(8.8)$ & $41(5.9)$ & 0.025 \\
\hline Mean stenosis & $36.7 \pm 16.9$ & $36.2 \pm 16.0$ & 0.801 \\
\hline \multicolumn{4}{|l|}{ LCX atherosclerosis } \\
\hline Any & $142(12.5)$ & $47(6.8)$ & $<0.001$ \\
\hline Significant (> 50\%) & $38(3.3)$ & $10(1.4)$ & 0.014 \\
\hline Mean stenosis & $37.1 \pm 16.9$ & $33.0 \pm 16.0$ & 0.203 \\
\hline \multicolumn{4}{|l|}{ RCA atherosclerosis } \\
\hline Any & 219 (19.2) & $89(12.8)$ & $<0.001$ \\
\hline Significant (> 50\%) & $54(4.7)$ & $16(2.3)$ & 0.008 \\
\hline Mean stenosis & $36.4 \pm 18.3$ & $32.2 \pm 14.9$ & 0.039 \\
\hline Result of ergonovine provocation test & & & $<0.001$ \\
\hline Definite & $493(43.2)$ & $178(25.5)$ & \\
\hline Intermediate & $648(56.8)$ & $519(74.5)$ & \\
\hline \multicolumn{4}{|l|}{ Discharge medication } \\
\hline Antiplatelet & $574(50.3)$ & $287(41.2)$ & $<0.001$ \\
\hline \multicolumn{4}{|l|}{ Calcium channel blocker } \\
\hline Dihydropyridine & $258(22.6)$ & $133(19.1)$ & 0.073 \\
\hline Non-dihydropyridine & $864(75.7)$ & $531(76.2)$ & 0.823 \\
\hline RAS blocker & $228(20.0)$ & $101(14.5)$ & 0.003 \\
\hline Beta-blocker & $68(6.0)$ & $49(7.0)$ & 0.362 \\
\hline Nitrate & $216(18.9)$ & $128(18.4)$ & 0.763 \\
\hline Nicorandil & $442(38.7)$ & $235(33.7)$ & 0.030 \\
\hline Molsidomine & $167(14.6)$ & $102(14.6)$ & 0.999 \\
\hline Trimetazidime & $103(9.0)$ & $101(14.5)$ & $<0.001$ \\
\hline Statin & $576(50.5)$ & $315(45.2)$ & 0.028 \\
\hline
\end{tabular}

Numbers are represented as mean $\pm S D$ or $n(\%)$. CAD Coronary artery disease, LDL Low-density lipoprotein, HDL High-density lipoprotein, EF Ejection fraction, $E C G$ Electrocardiogram, CAG Coronary angiography, $L M$ Left main, $L A D$ Left anterior descending artery, $L C X$ Left circumflex artery, RCA Right coronary artery, RAS Renin-angiotensin system

more frequently observed in male patients than in female patients. Although statistical significance was not reached, more cardiac arrest $(p=0.091)$ and syncope ( $p$ $=0.055)$ appeared in male. Compared to female patients, male patients had higher levels of hemoglobin, creatinine, glucose, and triglyceride, and had lower levels of total cholesterol, LDL cholesterol, and HDL cholesterol in blood. Left ventricular ejection fraction was within the normal limit and similar in both sexes. In ECG findings, ST segment elevation was more frequently observed in male patients, and $\mathrm{T}$ inversion was in female patients. In CAG findings, significant organic stenosis of the coronary artery was more frequently detected in male patients compared to female patients. The rate of definite diagnosis of VA by using EG provocation test was significantly higher in male patients than in female patients $(43.2 \%$ vs. $25.5 \%, p<0.001)$. Among discharge medications, antiplatelets, RAS blockers, nicorandil, and statin were more frequently prescribed in male patients, and trimetazidime in female patients.

\section{Clinical events}

The occurrence of clinical events is demonstrated in Table 2. During the median follow-up period of 760 days (interquartile range, 336-1105 days), there were 13 allcause death $(7.01 \%), 5$ cardiac death $(0.27 \%), 57$ acute coronary syndrome (3.10\%), 7 ventricular tachycardia/ fibrillation $(0.38 \%)$, and 6 atrioventricular block $(0.32 \%)$. Composite events occurred in 73 cases (3.97\%). In sex comparisons, cardiac death $(p=0.164)$ and ventricular tachycardia/fibrillation $(p=0.049)$ occurred in only male patients; the incidences of other events were similar between sexes ( $p>0.05$ for each). Independent risk factors for composite events are shown in Table 3. The presence 
Table 2 Clinical events

\begin{tabular}{llll}
\hline Clinical event & Male $(\boldsymbol{n}=\mathbf{1 1 4 1})$ & Female $(\boldsymbol{n}=\mathbf{6 9 7})$ & $\boldsymbol{p}$ value \\
\hline All-cause death & $7(0.6)$ & $5(0.7)$ & 0.697 \\
Composite events & $49(4.3)$ & $24(3.4)$ & 0.365 \\
$\quad$ Cardiac death & $5(0.4)$ & 0 & 0.164 \\
Acute coronary syndrome & $35(3.1)$ & $22(3.2)$ & 0.915 \\
$\quad$ Ventricular tachycardia or fibrillation & $7(0.6)$ & 0 & 0.049 \\
$\quad$ Atrioventricular block & $3(0.3)$ & $3(0.4)$ & 0.679 \\
\hline
\end{tabular}

Numbers are represented as $n$ (\%)

of significant organic stenosis was independently associated with both male (hazard ration [HR], 1.97; 95\% confidence interval $[\mathrm{CI}], 1.01-3.85 ; p=0.047$ ) and female (HR, 3.26; 95\% CI, 1.07-9.89; $p=0.037$ ) patients. The Kaplan-Meier event-free survival curve according to sex is demonstrated in Fig. 2. Even when only patients with definite diagnosis of VA were considered, there was no significant sex difference in clinical outcomes (log-rank $p=0.876)$ (Fig. 3). In female patients, higher BMI $(\geq 25$ $\mathrm{kg} / \mathrm{m}^{2}$ ) was associated with lower risk of composite events (HR, 0.22; 95\% CI, 0.07-0.68; $p=0.008$ ). Other factors such as age, cardiovascular risk factors, cigarette smoking, and the use of calcium channel blockers were not associated with VA outcomes in both sexes $(p>0.05$ for each). Kaplan-Meier event-free survival curves according to BMI and sex are demonstrated in Fig. 4. Characteristics of female patients with VA according to BMI are shown in Table 4.

\section{Discussion}

Using the nation-wide database, our study sought to find out sex differences in the clinical characteristics and long-term clinical outcomes of VA. Our main findings are as follows: (1) most of the patients diagnosed with VA were male; (2) male VA patients were younger, were more frequently smoker and alcohol drinker, and had more organic stenosis; (3) there was no significant sex difference in long-term cardiovascular outcomes; and (4) concomitant significant organic coronary stenosis was independent risk factor for worse prognosis in both sexes, and higher BMI was associated with better outcomes in females among VA patients.

\section{Previous studies on sex differences in VA}

Only a few studies have addressed sex differences in clinical characteristics and outcomes of VA [13-17]. In those studies, VA prevalence was significantly higher in males than in females: the range of proportion of females ranged from 12.7 to $24.0 \%$ [13-17]. The proportion of females was $37.9 \%$ in our study, which was higher in our study compared to previous studies. This might be due to the fact that we enrolled even patients with intermediate VA. Considering only patients with definite VA, the proportion of females was $26.5 \%$, similar to previous studies. Sueda et al. [16] investigated 204 Japanese patients with VA, and first reported less concomitant organic lesion and fewer focal spasm in female patients compared to male patients. In another study of 104 VA patients in Korea, there were no significant difference in clinical characteristics except for lower rate of smoking and alcohol consumption in female patients [17]. Zhu et al. [14] analyzed 209 Chinese patients with VA and demonstrated that female patients had a higher incidence of ventricular fibrillation during VA attack.

Table 3 Independent risk factors for cardiovascular events

\begin{tabular}{|c|c|c|c|c|}
\hline \multirow[t]{2}{*}{ Variable } & \multicolumn{2}{|l|}{ Male } & \multicolumn{2}{|l|}{ Female } \\
\hline & HR $(95 \% \mathrm{Cl})$ & $p$ value & $\mathrm{HR}(95 \% \mathrm{CI})$ & $p$ value \\
\hline Age $\geq 65$ years & $0.85(0.38-1.89)$ & 0.698 & $1.37(0.52-3.58)$ & 0.519 \\
\hline Body mass index $\geq 25 \mathrm{~kg} / \mathrm{m}^{2}$ & $1.07(0.58-1.95)$ & 0.819 & $0.22(0.07-0.68)$ & 0.008 \\
\hline Hypertension & $0.77(0.41-1.42)$ & 0.771 & $0.67(0.25-1.76)$ & 0.424 \\
\hline Diabetes mellitus & $1.65(0.73-3.72)$ & 0.222 & $0.57(0.07-4.47)$ & 0.598 \\
\hline Current cigarette smoking & $1.12(0.62-2.02)$ & 0.697 & $1.49(0.36-6.68)$ & 0.606 \\
\hline Significant atherosclerosis & $1.97(1.01-3.85)$ & 0.047 & $3.26(1.07-9.89)$ & 0.037 \\
\hline Definite spasm & $1.15(0.64-2.08)$ & 0.634 & $1.42(0.60-3.31)$ & 0.418 \\
\hline Non-dihydropyridine calcium channel blocker & $2.25(0.89-5.80)$ & 0.091 & $2.09(0.60-7.22)$ & 0.242 \\
\hline
\end{tabular}

HR Hazard ratio, Cl Confidence interval 


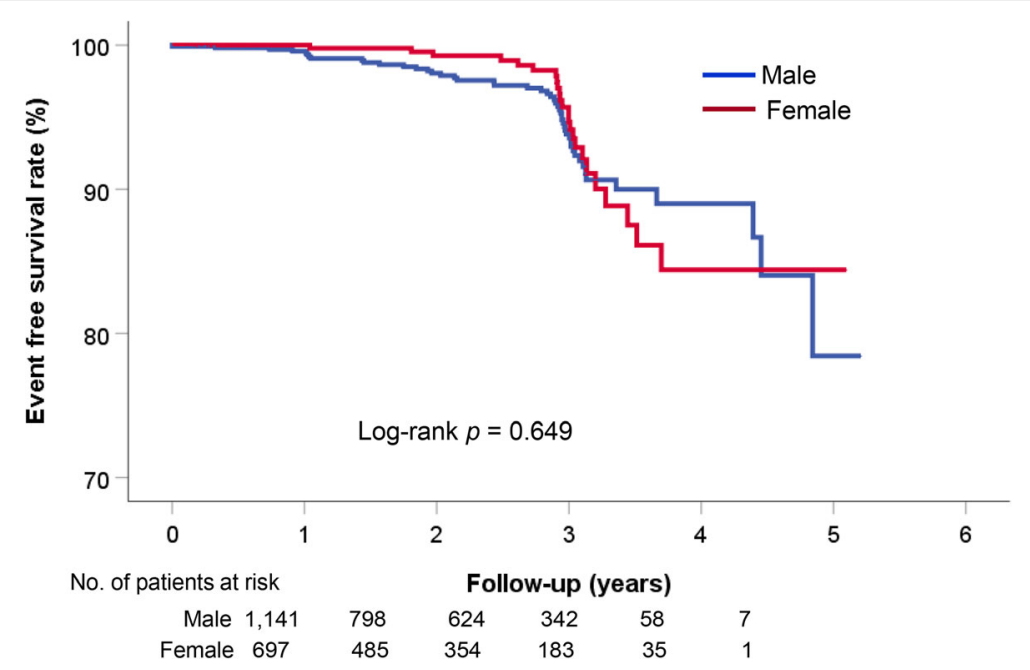

Fig. 2 Sex-specific long-term clinical outcomes in patients with vasospastic angina

Those small cross-sectional studies may be insufficient to show sex differences in VA clinical features. Two recent studies of a large number of VA patients analyzed the prognosis and clinical characteristics of VA $[13,15]$. A Japanese study of 1429 VA patients showed that female patients were characterized by old age, lower incidence of smoking, and less significant organic stenosis compared to male patients, and that the clinical outcomes of VA were similar between sexes [15]. Similarly, a Korean study of 986 VA patients demonstrated that female patients were younger and had a lower incidence of smoking or organic coronary stenosis than male patients [13]. In the same study, during the median followup period of 4.4 years, there were no significant differences in the occurrence of cardiovascular events between sexes [13]. Collectively, in most previous studies
$[9,13-15,17]$ and ours, VA prevalence is higher in males, and the more frequent cigarette smoking and alcohol drinking, and the greater the presence of fixed coronary lesions are common clinical feature of male VA patients compared to female patients. Also, cardiovascular outcomes of VA patients are similar between sexes $[13,15]$, which is in line with our results.

Sex differences in ECG changes are interesting. ST elevation was more frequently observed in men, which is the similar finding of a Japanese study [15]. Given that the rate of definite spasm was higher in men (Table 1), more frequent ST elevation may suggest more severe spasm in men. Underlying pathophysiology of more $\mathrm{T}$ inversion in women is still unknown. Further researches are needed to elucidate the mechanisms.

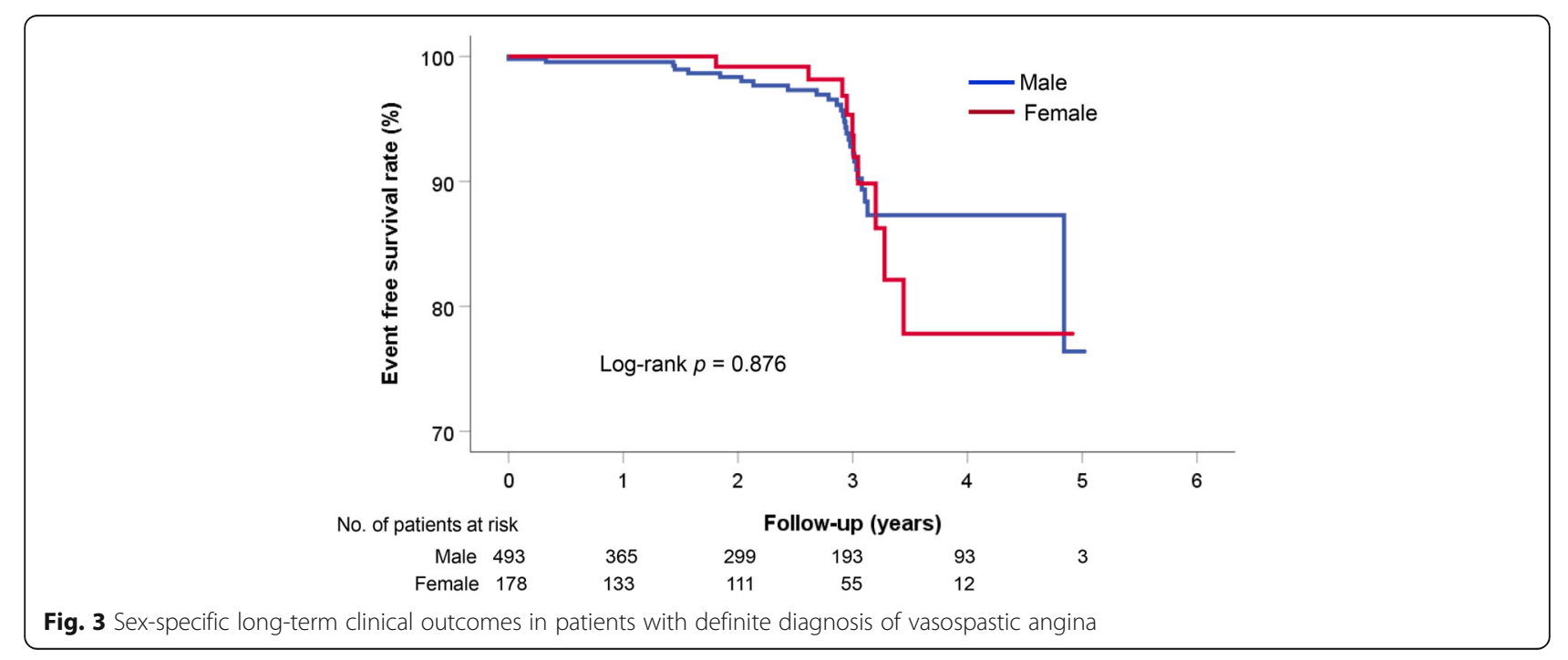




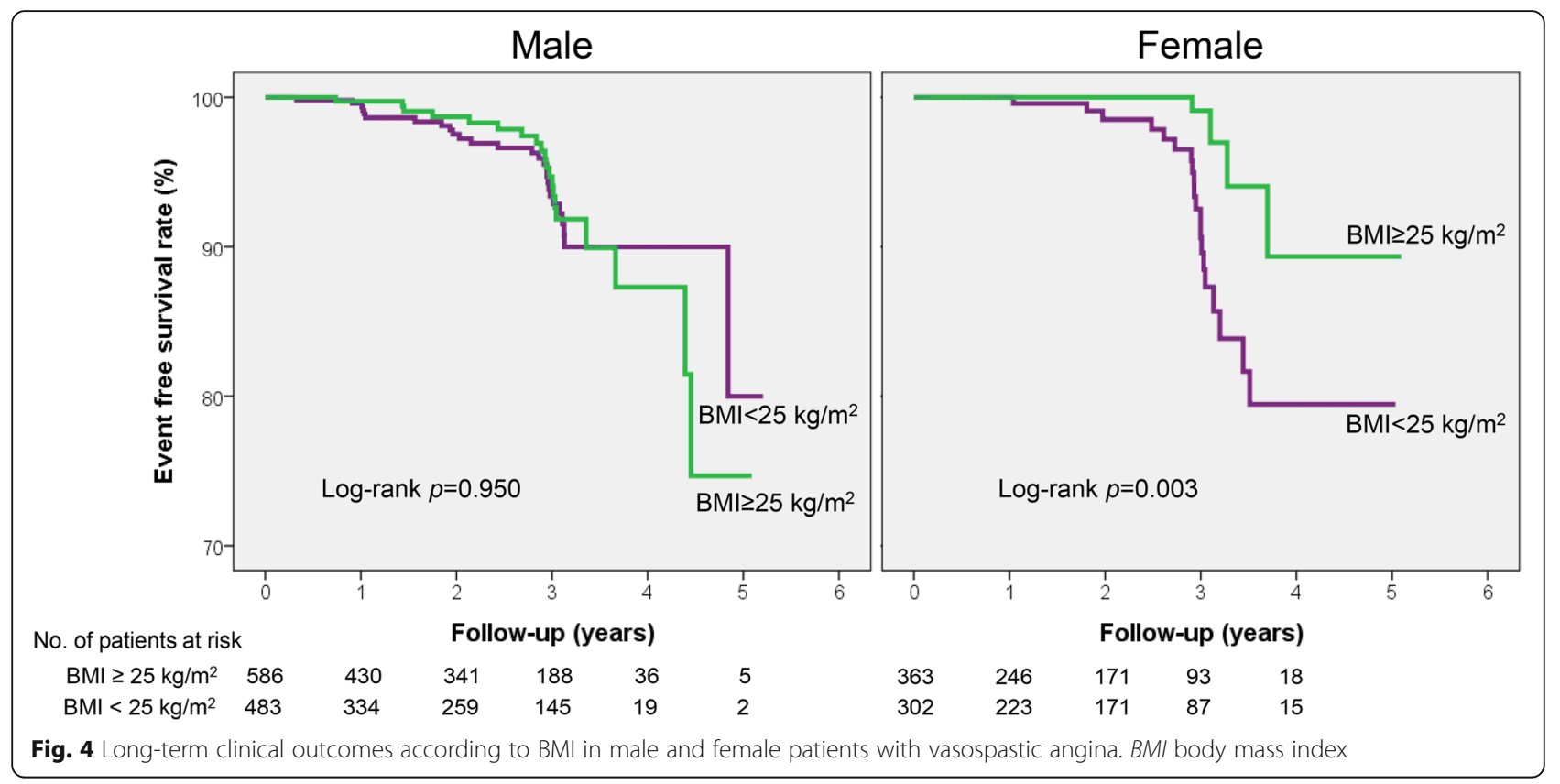

\section{Underlying pathophysiology}

Cigarette smoking and alcohol drinking are established risk factors for coronary spasm [2, 4, 22, 24], which may be an important factor explaining the higher prevalence of VA in men. Also, male VA patients more frequently have organic coronary stenosis $[9,13-15,17]$, which could affect the development of coronary artery spasm, because it is more likely to occur at the site of the coronary artery with atherosclerosis $[25,26]$. Previous studies $[13,15]$ and ours consistently showed that the occurrence of cardiovascular events during the longterm clinical follow-up was not different between sexes. In our study, more frequent organic coronary lesions and more serious cardiovascular events associated with VA at initial attack were observed in males; however, long-term prognosis was not worse compared to females. This lack of sex difference may have been attributed to the fact that female patients were older than male patients in our study. In addition, male patients were prescribed more antiplatelets, RAS blockers, and statins at discharge from the hospital, which may have contributed to improving patient' prognosis. Moreover, there could be the possibility that the use of vasodilators was effective and that the incidence of clinical events was too low to reach statistical significance. It is also necessary to consider that non-traditional risk factors (e.g., autoimmune and inflammatory disease, etc.), womenspecific risk factors (e.g., polycystic ovary syndrome, reproductive hormones, and pregnancy associated factors such as preterm delivery, gestational diabetes, gestational hypertension, preeclampsia and eclampsia, etc.), or emotional stress have influenced the prognosis of women
[27, 28]. Longer period follow-up studies of larger numbers of patients may be needed to clarify sex differences in VA clinical outcomes.

\section{Sex-specific prognostic factors}

Sex-specific prognostic factors for VA have not been clearly identified. In Japan, smoking, history of myocardial infarction, cardiac arrest, and organic coronary stenosis in male patients, as well as age and ventricular arrhythmia in female patients were associated with the occurrence of cardiovascular events during the long-term clinical followup [15]. In Korea, the high-sensitivity C-reactive protein level was an independent predictor of long-term clinical outcomes in male patients with VA, but not in female patients with VA [13]. The present study showed that significant organic coronary stenosis was an independent prognostic factor of VA in both sexes, which is in line with results of previous studies $[4,15,29,30]$. Interestingly, the novel finding of our study is that lower BMI was associated with worse clinical outcome in female with VA. Obesity is well known as a risk factor of atherosclerotic coronary artery disease in both males and females [31, 32], but its role in VA is still unknown. In our study, there is the possibility that less alcohol drinking, and more use of cardiovascular protective medications such as antiplatelets, renin-angiotensin system blockers, and statin, could at least in part play a role in improving VA prognosis in obese female patients (Table 4). In addition, increased estrogen production through aromatization of androgens in adipose tissue might play a role in more cardiovascular protection in obese women [33]. Further investigations 
Table 4 Characteristics of female patients with VA according to BMI

\begin{tabular}{|c|c|c|c|}
\hline Characteristic & $\mathrm{BMI}<25 \mathrm{~kg} / \mathrm{m}^{2}(n=364)$ & $\mathrm{BMI} \geq 25 \mathrm{~kg} / \mathrm{m}^{2}(n=303)$ & $p$ \\
\hline Age, years & $56.3 \pm 10.9$ & $57.7 \pm 10.4$ & 0.036 \\
\hline $\mathrm{BMI}, \mathrm{kg} / \mathrm{m}^{2}$ & $22.2 \pm 1.7$ & $27.9 \pm 3.4$ & $<0.001$ \\
\hline Systolic blood pressure, $\mathrm{mmHg}$ & $124 \pm 19$ & $123 \pm 17$ & 0.634 \\
\hline Diastolic blood pressure, $\mathrm{mmHg}$ & $75.4 \pm 12.3$ & $74.1 \pm 10.8$ & 0.173 \\
\hline \multicolumn{4}{|l|}{ Cardiovascular risk factors } \\
\hline Hypertension & $111(30.5)$ & $141(46.5)$ & $<0.001$ \\
\hline Diabetes mellitus & $16(4.4)$ & $37(12.2)$ & $<0.001$ \\
\hline Dyslipidemia & $55(15.2)$ & $66(21.9)$ & 0.026 \\
\hline Current smoking & $24(6.6)$ & $10(3.3)$ & 0.170 \\
\hline Alcohol drinking & $66(18.1)$ & $36(11.9)$ & 0.026 \\
\hline \multicolumn{4}{|l|}{ Clinical diagnosis } \\
\hline Acute myocardial infarction & $5(1.4)$ & $4(1.3)$ & 0.960 \\
\hline Cardiac arrest & $3(0.8)$ & $2(0.7)$ & 0.999 \\
\hline Syncope & $2(0.5)$ & $2(0.7)$ & 0.999 \\
\hline Ventricular tachycardia or fibrillation & $2(0.5)$ & $1(0.3)$ & 0.999 \\
\hline Significant atherosclerosis & $29(8.0)$ & $27(9.0)$ & 0.642 \\
\hline Definite spasm & $88(24.2)$ & $83(27.4)$ & 0.343 \\
\hline \multicolumn{4}{|l|}{ Laboratory findings } \\
\hline Hemoglobin, g/dL & $12.7 \pm 1.2$ & $12.9 \pm 1.2$ & 0.147 \\
\hline $\mathrm{GFR}, \mathrm{mL} / \mathrm{min} / 1.73 \mathrm{~m}^{2}$ & $104 \pm 48$ & $100 \pm 29$ & 0.136 \\
\hline Glucose, mg/dL & $105 \pm 38$ & $107 \pm 31$ & 0.502 \\
\hline Total cholesterol, mg/dL & $178 \pm 34$ & $177 \pm 37$ & 0.710 \\
\hline LDL cholesterol, mg/dL & $105 \pm 30$ & $107 \pm 32$ & 0.639 \\
\hline HDL cholesterol, mg/dL & $52.4 \pm 13.7$ & $48.0 \pm 11.7$ & $<0.001$ \\
\hline Triglyceride, mg/dL & $115 \pm 101$ & $132 \pm 74$ & 0.019 \\
\hline Left ventricular ejection fraction, \% & $64.4 \pm 6.2$ & $65.2 \pm 6.4$ & 0.126 \\
\hline \multicolumn{4}{|l|}{ Discharge medications } \\
\hline Antiplatelet & $138(38.2)$ & $141(46.5)$ & 0.030 \\
\hline Non-DHP calcium channel blocker & $282(77.5)$ & $222(73.3)$ & 0.208 \\
\hline Nitrate & $281(77.2)$ & $241(79.5)$ & 0.466 \\
\hline RAS blocker & $45(12.4)$ & $56(18.5)$ & 0.028 \\
\hline Statin & $156(42.9)$ & $153(50.5)$ & 0.049 \\
\hline
\end{tabular}

Numbers are represented as mean \pm SD or $n$ (\%). VA Vasospastic angina, BMI Body mass index, GFR Glomerular filtration rate, $L D L$ Low-density lipoprotein, $H D L$ High-density lipoprotein, DHP Non-dihydropyridine, RAS Renin-angiotensin system

into the sex-specific impact of BMI on the long-term clinical outcomes in VA patients are warranted.

\section{Study limitations}

This study has several limitations. First, due to the relatively small number of study patients, we analyzed not only the patients with definite diagnosis of VA but also those with intermediate diagnosis of VA. However, when we further analyzed only patients with definite diagnosis of VA, the main results were the same, showing that there was no sex difference in clinical outcome. Nevertheless, considering the low incidence of clinical events, it may be possible that sex differences in clinical outcome did not reach statistical significance due to the small number of patients or the short duration of clinical follow-up. Second, for the similar reason, some of the important variables, such as cardioprotective medications, were not controlled for during the multivariable analysis. Third, information on menopausal status in females was unavailable in our study, which would provide additional insight into sex differences in VA. Fourth, there was lack of information on drug adherence during clinical follow-up, which may have an impact on prognosis. Lastly, as our study patients were all Koreans; 
generalization of our result to other ethnic groups may be difficult.

\section{Perspectives and significance}

Although interest in sex differences in cardiovascular disease continues to increase, sex differences for VA are not well-known. Understanding sex differences is very important to improve patient prognosis through appropriate treatment. We showed that clinical outcome of VA is similar in spite of some different clinical characteristics between sexes. Significant organic coronary stenosis in both sexes and low BMI $\left(<25 \mathrm{~kg} / \mathrm{m}^{2}\right)$ in females were associated with worse prognosis in VA patients. Aggressive management of combined organic stenosis should be emphasized in VA patients. In female VA patients with low BMI $\left(<25 \mathrm{~kg} / \mathrm{m}^{2}\right)$, more attention should be paid to active treatment and monitoring to improve their clinical outcome.

\section{Conclusions}

Although there were several sex differences in clinical characteristics such as younger age, more frequent cigarette smoking and alcohol drinking, and more occurrence of concomitant organic coronary stenosis in males than in females, there was no sex different in long-term clinical outcome in VA patients. Concomitant organic stenosis was an independent predictor for long-term clinical outcome in both sexes. Aggressive management of concomitant organic stenosis should be emphasized in VA patients. A greater BMI was associated with better outcome only in female VA patients. Further studies on the sex-specific effects of BMI on prognosis in VA patients are needed.

\section{Acknowledgements}

None.

\section{Authors' contributions}

H-LK and S-HJ designed the research. H-LK wrote the manuscript. H-JK, M$\mathrm{HL}, \mathrm{S}-\mathrm{HB}$, and W-WS were involved in literature searches and manuscript editing. S-HJ revised the manuscript and had all responsibility of this study. All authors read and approved the final manuscript.

\section{Funding}

None.

\section{Availability of data and materials}

The data that support the findings of this study are available from the corresponding author upon reasonable request.

\section{Ethics approval and consent to participate}

The study protocol complied with the Declaration of Helsinki, and was approved by the Institutional Review Board of each participating hospital. Written informed consent was obtained from each patient.

\section{Consent for publication}

Not applicable.

\section{Competing interests}

The authors declare there is no conflict of interest associated with this manuscript.

\section{Author details}

'Division of Cardiology, Department of Internal Medicine, Boramae Medical Center, Seoul National University College of Medicine, Seoul, Korea. ${ }^{2}$ Division of Cardiology, Department of Internal Medicine, Hallym University Sacred Heart Hospital, Anyang, Korea. ${ }^{3}$ Department of Cardiology in Internal Medicine, Hanyang University Guri Hospital, Guri, Korea. ${ }^{4}$ Department of Cardiovascular Medicine, Soonchunhyang Seoul Hospital, Seoul, Korea. ${ }^{5}$ Department of Cardiovascular Medicine, Hallym University Kangdong Hospital, Seoul, Korea. ${ }^{6}$ Department of Cardiovascular Medicine, Seoul St. Mary's Hospital, The Catholic University of Korea, Seoul, Korea.

Received: 3 September 2020 Accepted: 9 November 2020

Published online: 23 November 2020

\section{References}

1. Stern S, Bayes de Luna A. Coronary artery spasm: a 2009 update. Circulation. 2009:119:2531-4.

2. Yasue $H$, Nakagawa $H$, Itoh T, Harada E, Mizuno Y. Coronary artery spasmclinical features, diagnosis, pathogenesis, and treatment. J Cardiol. 2008;51: 2-17.

3. Crea F, Lanza GA. New light on a forgotten disease: vasospastic angina. J Am Coll Cardiol. 2011;58:1238-40.

4. Yasue H, Takizawa A, Nagao M, Nishida S, Horie M, Kubota J, Omote S, Takaoka K, Okumura K. Long-term prognosis for patients with variant angina and influential factors. Circulation. 1988;78:1-9.

5. Ludmer PL, Selwyn AP, Shook TL, Wayne RR, Mudge GH, Alexander RW, Ganz P. Paradoxical vasoconstriction induced by acetylcholine in atherosclerotic coronary arteries. N Engl J Med. 1986;315:1046-51.

6. Yasue H, Kugiyama K. Coronary spasm: clinical features and pathogenesis. Intern Med. 1997:36:760-5.

7. Hung MJ, Cheng CW, Yang NI, Hung MY, Cherng WJ. Coronary vasospasminduced acute coronary syndrome complicated by life-threatening cardiac arrhythmias in patients without hemodynamically significant coronary artery disease. Int J Cardiol. 2007;117:37-44.

8. Myerburg RJ, Kessler KM, Mallon SM, Cox MM, de Marchena E, Interian A Jr, A Castellanos. Life-threatening ventricular arrhythmias in patients with silent myocardial ischemia due to coronary-artery spasm. N Engl J Med. 1992;326: 1451-1455.

9. Mosca L, Barrett-Connor E, Wenger NK. Sex/gender differences in cardiovascular disease prevention: what a difference a decade makes. Circulation. 2011:124:2145-54.

10. EUGenMed Cardiovascular Clinical Study Group, Regitz-Zagrosek V, OerteltPrigione S, Prescott E, Franconi F, Gerdts E, Foryst-Ludwig A, et al. Gender in cardiovascular diseases: impact on clinical manifestations, management, and outcomes. Eur Heart J. 2016;37:24-34.

11. Bugiardini R, Manfrini O, Pizzi C, Fontana F, Morgagni G. Endothelial function predicts future development of coronary artery disease: a study of women with chest pain and normal coronary angiograms. Circulation. 2004; 109:2518-23.

12. Pepine CJ, Anderson RD, Sharaf BL, Reis SE, Smith KM, Handberg EM, et al. Coronary microvascular reactivity to adenosine predicts adverse outcome in women evaluated for suspected ischemia results from the National Heart, Lung and Blood Institute WISE (Women's Ischemia Syndrome Evaluation) study. J Am Coll Cardiol. 2010;55:2825-32.

13. Lee DH, Park TK, Seong CS, Gwag HB, Lim AY, Oh MS, et al. Gender differences in long-term clinical outcomes and prognostic factors in patients with vasospastic angina. Int J Cardiol. 2017;249:6-11.

14. Zhu CG, Li JJ, Xu YL, Yuan JQ, Qin XW, Yang YJ, et al. Gender difference of clinical characteristics in Chinese patients with spontaneous variant angina. Chin Med J. 2010;123:1377-81.

15. Kawana A, Takahashi J, Takagi Y, Yasuda S, Sakata Y, Tsunoda R. et al; Japanese Coronary Spasm Association. Gender differences in the clinical characteristics and outcomes of patients with vasospastic angina-a report from the Japanese Coronary Spasm Association. Circ J. 2013;77:1267-74.

16. Sueda S, Suzuki J, Watanabe K, Mineoi K, Kondou T, Yano K, et al. Clinical characteristics of female patients with coronary spastic angina: comparison with male patients. Jpn Circ J. 2000;64:416-20.

17. Lee JH, Lee H, Bae MH, Kwon YS, Lee JH, Ryu HM, et al. Gender differences among Korean patients with coronary spasm. Korean Circ J. 2009;39:423-7.

18. Shin Dl, Baek SH, Her SH, Han SH, Ahn Y, Park KH, et al. The 24-month prognosis of patients with positive or intermediate results in the 
intracoronary ergonovine provocation test. JACC Cardiovasc Interv. 2015;8: 914-23.

19. Han SH, Lee KY, Her SH, Ahn Y, Park KH, Kim DS, et al. Impact of multi-vessel vasospastic angina on cardiovascular outcome. Atherosclerosis. 2019;281: 107-13.

20. Cho SS, Jo SH, Han SH, Lee KY, Her SH, Lee MH, et al. Clopidogrel plus aspirin use is associated with worse long-term outcomes, but aspirin use alone is safe in patients with vasospastic angina: results from the VA-Korea registry, a prospective multi-center cohort. Sci Rep. 2019;9:17783.

21. Scanlon PJ, Faxon DP, Audet AM, Carabello B, Dehmer GJ, Eagle KA, et al. ACC/AHA guidelines for coronary angiography. A report of the American College of Cardiology/American Heart Association Task Force on practice guidelines (Committee on Coronary Angiography). Developed in collaboration with the Society for Cardiac Angiography and Interventions. J Am Coll Cardiol. 1999:33:1756-824.

22. JCS Joint Working Group. Guidelines for diagnosis and treatment of patients with vasospastic angina (Coronary Spastic Angina) (JCS 2013). Circ J. 2014; 78:2779-801.

23. Kumar A, Cannon CP. Acute coronary syndromes: diagnosis and management, part I. Mayo Clin Proc. 2009;84:917-38.

24. Sugiishi M, Takatsu F. Cigarette smoking is a major risk factor for coronary spasm. Circulation. 1993;87:76-9.

25. Ozaki Y, Keane D, Serruys PW. Progression and regression of coronary stenosis in the long-term follow-up of vasospastic angina. Circulation. 1995; 92:2446-56.

26. Yamagishi M, Miyatake K, Tamai J, Nakatani S, Koyama J, Nissen SE. Intravascular ultrasound detection of atherosclerosis at the site of focal vasospasm in angiographically normal or minimally narrowed coronary segments. J Am Coll Cardiol. 1994;23:352-7.

27. Gulati M. Improving the cardiovascular health of women in the nation: moving beyond the bikini boundaries. Circulation. 2017;135:495-8

28. Mass AH, Appelman YE. Gender differences in coronary heart disease. Neth Heart J. 2010;18:598-602

29. Waters DD, Miller DD, Szlachcic J, Bouchard A, Methe M, Kreeft J, et al. Factors influencing the long-term prognosis of treated patients with variant angina. Circulation. 1983;68:258-65.

30. Choi JC, Cha KS, Lee HW, Yun EY, Ahn JH, Kim JH, et al. Prognostic factors in patients with proven or possible vasospastic angina who underwent coronary spasm provocation test. Int J Cardiol. 2013;168:3044-5.

31. Mongraw-Chaffin ML, Peters SAE, Huxley RR, Woodward M. The sex-specific association between $\mathrm{BMI}$ and coronary heart disease: a systematic review and meta-analysis of 95 cohorts with 1.2 million participants. Lancet Diabetes Endocrinol. 2015;3:437-49.

32. Choi S, Kim K, Kim SM, Lee G, Jeong SM, Park SY, et al. Association of obesity or weight change with coronary heart disease among young adults in South Korea. JAMA Intern Med. 2018;178:1060-8.

33. Cleary MP, Grossman ME. Minireview: Obesity and breast cancer: the estrogen connection. Endocrinology. 2009;150:2537-42

\section{Publisher's Note}

Springer Nature remains neutral with regard to jurisdictional claims in published maps and institutional affiliations.

Ready to submit your research? Choose BMC and benefit from:

- fast, convenient online submission

- thorough peer review by experienced researchers in your field

- rapid publication on acceptance

- support for research data, including large and complex data types

- gold Open Access which fosters wider collaboration and increased citations

- maximum visibility for your research: over $100 \mathrm{M}$ website views per year

At $\mathrm{BMC}$, research is always in progress.

Learn more biomedcentral.com/submissions 